\title{
YOUR BEST VIRTUAL SELF-IMPROVEMENT. THE USE OF VIRTUAL REALITY IN STRESS MANAGEMENT TRAINING
}

\author{
Alessandro De Carlo ${ }^{1}$, Sebastiano Rapisarda ${ }^{2}$, Diletta Mora ${ }^{3}$, \& Paula Benevene ${ }^{2}$ \\ ${ }^{1}$ Università Giustino Fortunato (Italy) \\ ${ }^{2}$ LUMSA University of Rome (Italy) \\ ${ }^{3}$ PSIOP Institute (Italy)
}

\begin{abstract}
Virtual reality can be used as a tool for enhancing psychological interventions in organizations, increasing their efficacy and efficiency, thus making psychology more compelling and competitive.

Stress management is a fundamental skill for managers, forced to deal on a daily basis with complex, fast and demanding environments and tasks. Managers are not only entitled to increase company revenues; their psychological well-being and ability to cope with stress reflects directly on workers' psychological health. Organizational psychology developed many techniques in order to help managers deal with stress, especially through specific training activities.

The aim of the present study is to explore the effects of a specific training on stress management, conducted on managers with the aid of a virtual reality device.

A sample of managers was trained in imagining their best possible self, and in using this thought to increase positive future expectancies. This training was conducted in three consequent virtual reality environments. The first environment, a relaxing open space of choice (e.g. a lake side), was used in the opening part of the training, in order to help managers find a relaxed state of mind for thinking about their possible self. The second environment, a happy place (a real place relevant in the manager's life), was used in order to help managers imagine their stress-management skills and understand how to use them in difficult situations. The third environment, a place not yet visited but desired, was used in the closing part of the training for linking the training to a desirable future.

Interviews and questionnaires on the managers' environment and stressors in their job, estimated stress-management skills, and self-efficacy were carried out before and after the training. A follow up interview on the same topics was conducted three weeks after the training. Satisfaction for the training was also investigated.

The data obtained were examined through both qualitative and quantitative analyses. The managers reported a high level of satisfaction for the training, specifically related with the use of virtual environments. The training was perceived as effective in increasing stress-management skills, both just after its completion and after three weeks. The managers felt a higher degree of self-efficacy regarding their ability to cope with stress in complex situations.

Virtual reality is an effective tool not just for improving psychological intervention, but also for making it more appealing. Therefore, it is a technology that should be further studied and introduced in professional practice.
\end{abstract}

Keywords: Virtual reality, training, stress-management, organizational well-being, self-improvement.

\section{Introduction}

\subsection{Stress and health}

The current socio-economic context leads to new challenges and opportunities for organizations. The aim of new working practices is to improve quality and productivity (Colombo \& Gallego, 2012). Health and well-being have become a key variable in organizational psychology, including behavioral, affective and cognitive components, such as ability, autonomy and positive and negative affectivity. The latter, paired with optimism, is relevant because of its relationships with various constructs related to work, such as job satisfaction, work-related stress, job burnout and work-family conflict (Russell \& Daniels, 2018).

\subsection{Virtual reality and psychology}

Virtual reality (VR) applied to psychology is now enjoying a good reception by scholars and the professional community, especially in the clinical setting for phobias (Botella, Hofman, \& Moscovitch, 2004), general stress from chemotherapy (Schneider, Kisby, \& Flint, 2011), pain perception (Espinoza et 
al., 2012) including burn patients who underwent VR sessions to distract them from pain and anxiety during burn treatment (Eccleston \& Crombez, 1999), normally patients who experience severe burns and who undergo physical therapy spend $75 \%$ of the duration of the therapy focusing on pain, when the same patients undergoing VR therapy spend only $25 \%$ of it (Hoffman et al., 2001), anxiety and depression levels in cancer patients (Chirico et al., 2015) post-traumatic stress disorder (Beidel et.al., 2019).

Interventions based on the use of immersive audiovisual technologies have the ability to emotionally engage the person, capture their attention and direct them towards new stimuli (Nichols \& Patel 2002; Gamberini et al., 2015). The potential also lies in the fact that these technologies are particularly suitable for situations of poor mobility or attention span. The immersive and interactive virtual environments can be used to expose the patient to stressful situations, exactly like an expositive therapy, but in total safety.

\subsection{Virtual reality and stress in organizations}

The most advanced systems available also extend their applications to the world of work, with innovative technical features developed specifically for professional use (compared to the widespread use of adapted generalist devices). Some authors have investigated the influence and application of virtual reality in organizations for work well-being. Some of these studies highlight how this technology can be considered a valid tool for relaxation techniques. The outcomes show a decrease of work stress due to immersion in beautiful natural scenarios, body scan, deep breathing and psychoeducation using virtual reality (Anderson, Mayer, Fellows, Cowan, Hegel, \& Buckey, 2017). However, the use of virtual reality is very extensive and also embraces the world of training. For example, using programs for stress management has increased in various fields, like the military, whose activities, often complex and stressful, require a high cognitive and emotional effort. The aim is to improve resilience and provide a primary stress prevention. In recent years, several studies have evaluated the effectiveness of these trainings that use VR as a tool for their accomplishment and the results show that this technology allows to reduce the perception of stress and negative affectivity in military personnel (Pallavicini, Argenton, Toniazzi, Aceti, \& Mantovani, 2016). Gradual exposure using virtual environments can improve allostasis and develop calmer and resilient behavior (Finseth, Keren, Dorneich, Franke, Anderson, $\&$ Shelley, 2018). Another area of intervention refers to training on health and safety in the workplace. The goal is to better understand the potential danger of the job activities and any prevention options. In this area, simulating the working context in a virtual environment and interacting with it allows users to fully immerse themselves and have greater benefits from training. In addition, employees perceive VR training as more efficient, less expensive, more attractive and more optimized than classic training without VR (Janak, Cmorej, Vysocky, Kocisko, \& Teliskova, 2016). Furthermore, virtual reality has been used to increase empathy, resilience and the ability to make decisions in moral dilemma situations. Simulating moral dilemma situations in virtual environments helps both understand the actions and behaviors of professionals, and help them through specific training at a later stage (Francis, Gummerum, Ganis, Howard, \& Terbeck, 2017).

\subsection{The best possible self}

The best possible self (BPS) activity, from his outset in 2001, has been the focus of studies which have proven it to be a feasible intervention to enhance optimism, positive affectivity, health and well-being. The BPS intervention can be effective when administered in-person or on-line and repeating the activity appears to enhance efficacy (Meevissen, Peters, \& Alberts 2011; Loveday, Lovell, Jones, 2016). Investigating the literature, Loveday et al. (2016), found that BPS represents an extremely effectual intervention. In addition, it is flexible with regards to the delivery method (on-line or face to face) without costs in terms of efficacy. Furthermore, as it is recommended that psychological stress-management interventions should include multiple techniques as rather than a single one (Wang, Smith, Ashley, \& Hyland, 2019), the BPS can be recommended as one in a portfolio of interventions and, when used and repeated over time, can lead to a significant increase in well-being, which can persist over time.

\section{Method}

A group of 9 managers active in the field of public and private services was trained in imagining their best possible self, and in using this thought to increase positive future expectancies. This training was conducted in one session and was divided in three phases, paired with the use of three different virtual reality environments, administered using a dedicated visor.

The first environment, a relaxing open space of choice (e.g. a lake side), was used in the opening part of the training, in order to help managers find a relaxed state of mind for thinking about their possible self. The second environment, a happy place of choice (a real place relevant in the manager's life), was used in order to help managers imagine their stress-management skills and understand how to use them in difficult situations. Examples of environments used in this phase: managers' home, managers' company 
building, airport. The third environment, a place not yet visited but desired, was used in the closing part of the training for linking the training to a desirable future. Examples of environments used in this phase: Times' Square in New York, Beach in Maldives, Petra's ruins.

The first environment was embedded in the virtual reality system, the two real places of managers' choice were found using a function of the VR kit named "teleporting", which is linked to Google Street View.

The study was conducted in 4 steps:

1) Interview on manager's thoughts about stress and on their stress management skills (e.g. try to describe a stressful situation typical of your job through an image or a metaphor; How much do you feel able to manage this stress?; Critical Incident Technique) and questionnaire about their perceived levels of stress and stress management skills with answers on a scale from 1 to 10 . The managers were also asked to locate a place that they perceived as happy for themselves as well as a place they wished to visit.

2) Application of a 55 minutes training based on the Best Possible Self technique and the exposure to the three consequential virtual environments aimed at facilitating the progression of thoughts from the different possible selves to the best possible self.

3) Interview on satisfaction for the training (e.g. How satisfied are you with the training just received? What is the aspect of VR training that you appreciate most? How much do you think the training received can help you learn to manage stress?).

4) Telephone follow-up interview on one's perception of stress management skills (e.g. In the period of time that has passed, how much did you feel able to manage stress?) and satisfaction for the training.

Qualitative content analysis was applied to the interviews, and relevant sentences were isolated in order to create a set of phrases that could be useful to understand the different thoughts of the participants on the topics object of investigation.

Mean and standard deviation of the answers to the questionnaires have been recorded due to the size of the sample.

\section{Results}

\subsection{Pre-training interview and questionnaire}

Managers pictured stress as a strong concern for their health and for their activities, describing it as "fear of running out of power and losing control"; "path on the ash, where the sun shines very rarely, but above all a path in which you travel alone", "entering a cloud and not seeing the horizon, as in the mountains in bad weather", an "assembly line and a boulder that sits right on your chest", a "responsibility", a "green lawn with people waiting for something to happen [...] but they just wait, as if they lacked the assumption of responsibility". 7 out of 9 managers expressed a seriously worried attitude towards stress.

The participants also described their stress management tools: Management of emotions, "using adequate, controlled language and tones of voice"; "Try to convey my calmness to the other"; taking "a point of view unrelated to mine, so that I can see myself from outside, as if I were looking at my behavior through the collaborator's eyes"; "High rate of creativity. We must always find innovative, non-mechanical solutions. I also use a lot the sharing with the collaborators of the processes that lead me to make the final decision; without of course this meaning sharing responsibility"; "Go into detail: what's the problem? Why did the process stop, why didn't that particular answer come? I often use my authority, but very little my authority". The whole group of managers expressed the perception of having a certain degree of skill in managing stress, 7 out of 9 of them wanted to improve their skills and abilities in this area.

The perceived organizational stress and stress management capabilities, investigated through a questionnaire are summarized in Table 1.

Table 1. Perceived organizational stress and stress management capabilities.

\begin{tabular}{|l|l|l|}
\hline & Mean & SD \\
\hline $\begin{array}{l}\text { In stressful situations, on a scale of 1 to 10, how much do you } \\
\text { feel capable of handling this stress? }\end{array}$ & 7.00 & 1.79 \\
\hline How good you perceive your stress-management skills are? & 7.40 & 1.40 \\
\hline
\end{tabular}

\subsection{Post-training interview and questionnaire}

Participants described the perceived relevance for organizations of the training they received: "I think it is useful for companies, but always accompanied by a professional, for example by combining it with an interview, as on this occasion. This is because the interview helped me to focus on some aspects of my management skills and habits that otherwise I would not have brought to awareness"; 
"Undoubtedly a useful tool, but I would combine it with something else. For example, first I would understand the levels of stress and the problems that the worker is facing"; "It seems to me especially useful for involving, attracting and starting people to carry out these practices"; "It is especially useful for bringing people together. I, for example, traditionally would not do relaxation excercises; with this tool yes"; "It can help you experiment with new ways of concentration, even with yourself, which is useful for people with particular relaxation difficulties"; "I would see it useful in a perspective of enhancement. The important thing is to explicitly link this activity to the resulting benefit"; "I think that with a little training these techniques can also help increase performance"; "I would recommend it especially for the most critical areas, after having investigated and recognized them as such. It can also be an experiment that starts from the small one and then involves the whole organization in cascade"; "I would use it for non-top managers, such as middle managers, but not for the top roles. Practically for the figures who experience the most interpersonal stress. Also, because usually these figures are a target that for age, education and history could be more intrigued".

The satisfaction for the training and its usefulness, investigated through a questionnaire are summarized in Table 2.

Table 2. Satisfaction for the training and its usefulness.

\begin{tabular}{|c|c|c|}
\hline & Mean & SD \\
\hline $\begin{array}{c}\text { On a scale of } 1 \text { to 10, how satisfied are you with } \\
\text { the training just received? }\end{array}$ & 8.80 & 1.28 \\
\hline $\begin{array}{c}\text { How much do you think the training you received } \\
\text { can help you learn to manage stress? }\end{array}$ & 8.10 & 10 \\
\hline
\end{tabular}

\subsection{Follow up interview}

In the telephone interview conducted two weeks after the training, managers declare to have maintained the levels of efficacy perceived at the end of the training. "I feel like I've learnt techniques that are here to stay"; "I found myself thinking often to what I've learnt and how to apply it everyday"; "It happened to me to find myself applying the thoughts of the training"; "Whenever I start being less positive about myself or the future, I go back to the training and the feeling starts changing". They also declared a perception of better stress management skills. "The exercise helped me managing my stress levels"; "Thinking about my best possible self helps me finding focus and peace when things are quite stressful".

\section{Discussion}

The study shows how a training based on the Best Possible Self technique paired with the exposure to virtual reality can be a useful tool for enhancing optimism and helping workers in managing stress. While literature is strong in the effectiveness of traditional training, the pairing between it and virtual reality is a new development that can have a widespread diffusion. The effects of virtual reality in enhancing the effects of training, as well as counseling and intervention, are to be expected in the Best Possible Self based training as well. The group of managers that took part to this exploratory study expressed many thoughts that are useful for directing further studies as well as for understanding more deeply the feelings that the use of VR causes while paired to traditional training.

Limits: The study is preliminary and exploratory. There is need of investigating bigger sample, of using control groups, and to apply deeper quantitative analyses on bigger data sets in order to obtain generalizable results. A vaster range of different virtual environments tested is also needed.

Innovation: The use of VR, with its intrinsic innovative technical characteristics, stands promisingly among the applications of psychology in the organizational context It will allow: Greater effectiveness in interventions, greater penetration and engagement, increased possibilities for professional action. There is the need of developing more VR based intervention protocols as well as methodologies for studying their effectiveness as well as their likeability and attractiveness within working environments.

\section{References}

Anderson, A.P., Mayer, M.D., Fellows, A.M., Cowan, D.R., Hegel, M.T., \&amp; Buckey, J.C. (2017). Relaxation with immersive natural scenes presented using virtual reality. Aerospace Medicine and Human Performance, 88(6), 520-526.

Beidel, D.C., Frueh, B.C., Neer, S.M., Bowers, C.A., Trachik, B., Uhde, T.W., et al. (2019). Trauma management therapy with virtual-reality augmented exposure therapy for combat-related PTSD: A randomized controlled trial. Journal of Anxiety Disorders, 61, 64-74. 
Botella, C., Hofman, S.G., \& Moscovitch, D.A. (2004). A self-applied, Internet-based intervention for fear of public speaking. Journal of Clinical Psychology, 60(8), 821-30.

Brosschot, J.F., Pieper, S., \& Thayer, J.F. (2005). Expanding stress theory: Prolonged activation and preservative cognition. Psychoneuroendocrinology, 90, 1054-1068s.

Chirico, A., Yaden, D.B., Riva, G., \& Gaggioli, A. (2015). The Potential of Virtual Reality for the Investigation of Awe. Frontiers in Psychology, 7, 1766

Colombo, V., \&amp; Gallego, E.C. (2012). The importance of recovery from work: A review of where, how and why. Papeles del Psicólogo, 33(2), 129-197.

Eccleston, C., \& Crombez, G. (1999). Pain demands attention: a cognitive-affective model of the interruptive function of pain. Psychological Bullettin, 125(3), 356-366.

Espinoza, M., Baños, R.M., García-palacios, A., Cervera, J.M., Esquerdo, G., Barrajón, E., et al. (2012). Promotion of emotional wellbeing in oncology inpatients using VR. Annual Review of Cybertherapy and Telemedicine, 53-57

Finseth, T.T., Keren, N., Dorneich, M.C., Franke, W.D., Anderson, C.D., \&amp; Shelley, M.C. (2018). Evaluating the effectiveness of graduated stress exposure in virtual spaceflight hazard training. Journal of Cognitive Engineering and Decision Making, 12(4), 248-268.

Francis, K.B., Gummerum, M., Ganis, G., Howard, I.S., \&amp; Terbeck, S. (2018). Virtual morality in the helping professions: Simulated action and resilience. British Journal of Psychology I, 109, 442-465.

Gamberini, L.., Chittaro, L.., Spagnolli, A., \& Carlesso, C. (2015). Psychological response to an emergency in virtual reality: Effects of victim ethnicity and emergency type on helping behavior and navigation. Computers in Human Behavior, 48, 104-113.

Hobfoll, S.E. (1998). Stress, culture, and community: The psychology and physiology of stress. New York: Plenum Press.

Hoffman, H.G., Patterson, D.R., Carrougher, G.J., Nakamura, D., Moore, M., \& Garcia-Palacios, A. (2001). The effectiveness of virtual reality pain control with multiple treatments of longer durations: A case study. International Journal of Human-computer Interaction, 13(1), 1-12.

Janak, M., Cmorej, T., Vysochy, T., Kocisko, M., \&amp; Teliskova, M. (2016). Virtual Reality as an effective simulation tool for OSH education on robotized workplace. MATEC Web of Conferences, 68.

Loveday, P., Lovell, G., \&amp; Jones, C. (2016). The Best Possible Selves Intervention: A Review of the Literature to Evaluate Efficacy and Guide Future Research. Journal of Happiness Studies.

Meevissen, Y. M. C., Peters, M. L., \& Alberts, H. J. E. M. (2011). Become more optimistic by imagining a best possible self: Effects of a two week intervention. Journal of Behavior Therapy and Experimental Psychiatry, 42, 371-378.

Meijman, T.F., \& Mulder, G. (1998). Psychological aspects of workload. In P.J.D. Drenth \& H. Thierry (Eds.), Handbook of work and organizational psychology (Vol. 2: Work psychology, pp. 5-33). Hove, England: Psychology Press.

Nichols, S., \& Patel, H. (2002). Health and safety implications of virtual reality: a review of empirical evidence. Applied Ergonomics, 33(3), 251-71.

Pallavicini, F., Argenton, L., Toniazzi, N., Aceti, L., \&amp; Mantovani, F. (2016). Virtual reality applications for stress management training in the military. Aerospace Medicine and Human Performance, 89(12), 1-10.

Russell, E., \&amp; Daniels, K. (2018). Measuring affective well-being at work using short-form scales: Implications for affective structures and participant instructions. Human Relations, 71(11), $1478-1507$.

Sawhney, G., Jennings, K.S., \& Britt, T.W. (2017). Occupational stress and mental health symptoms: Examining the moderating effect of work recovery strategies in firefighters. Journal of Occupational Health Psychology, 23(3), 443-456.

Schneider, S.M., Kisby, C.K., \& Flint, E.P. (2011). Effect of virtual reality on time perception in patients receiving chemotherapy. Support Care Cancer, 19(4), 555-64.

Sonnetag, S., \& Fritz, C. (2007). The recovery experience questionnaire: Development and validation of a measure for assessing recuperation and unwinding from work. Journal of Occupational Health Psychology, 12(3), 204-221.

Wang, X., Smith, C., Ashley, L., \&amp; Hyland, M. (2019). Tailoring Self-Help Mindfulness and Relaxation Techniques for Stroke Survivors: Examining Preferences, Feasibility and Acceptability. Frontiers in Psychology, 10. 